Original Article

\title{
Relationship between hamstring length and gluteus maximus strength with and without normalization
}

\author{
Dong-Kyu Lee, PT, $\mathrm{PhD}^{1)}$, JAe-Seop OH, PT, $\mathrm{PhD}^{2)^{*}}$ \\ 1) Department of Physical Therapy, Graduate School, Inje University, Republic of Korea \\ 2) Department of Physical Therapy, College of Biomedical Science and Engineering, Inje University: \\ 607 Obang-dong, Gimhae-si, Gyeongsangnam-do 621-749, Republic of Korea
}

\begin{abstract}
Purpose] This study assessed the relationship between hamstring length and gluteus maximus (GM) strength with and without normalization by body weight and height. [Subjects and Methods] In total, 34 healthy male subjects volunteered for this study. To measure GM strength, subjects performed maximal hip joint extension with the knee joints flexed to $90^{\circ}$ in the prone position. GM strength was normalized for body weight and height. [Results] GM strength with normalization was positively correlated with hamstring length, whereas GM strength without normalization was negatively correlated with hamstring length. [Conclusion] The normalization of GM strength by body weight and height has the potential to lead to more appropriate conclusions and interpretations about its correlation with hamstring length. Hamstring length may be related to GM strength.

Key words: Gluteus maximus strength, Hamstring length, Normalization
\end{abstract}

(This article was submitted Sep. 5, 2017, and was accepted Oct. 18, 2017)

\section{INTRODUCTION}

Muscle strength measurement is widely regarded as an important tool for the assessment of musculoskeletal dysfunction ${ }^{1)}$. A hand-held dynamometer (HHD) is a portable measurement device used for the quantitative assessment of muscle strength ${ }^{2)}$. However, the inability of researchers to stabilize the HHD against larger muscle groups can result in great variability among trials. Previous studies have thus advocated the use of portable fixed dynamometry ${ }^{3)}$.

The gluteus maximus (GM) and hamstring muscles are synergists for hip extension. If the GM is weak, the hamstring often acts as the primary hip extensor to compensate for GM weakness ${ }^{4}$. Hamstring tightness in individuals with low back pain could be a compensatory mechanism for weak gluteal muscles, as the hamstring and gluteal muscles have common attachments to the ischial tuberosity and sacrotuberous ligament ${ }^{5}$. Massoud Arab et al. ${ }^{6}$ reported that hamstring tightness in subjects with sacroiliac joint dysfunction could be related to gluteal muscle weakness.

Muscle strength is strongly influenced by body size and is correlated with measures such as body mass and height ${ }^{7}$. Strength measurements have traditionally been normalized to measures of body size to remove body size dependence. However, a recent review showed that most data reported in the literature were either not normalized or normalized using inappropriate methods ${ }^{8)}$. Without appropriate normalization, body size parameters may confound the data, making meaningful comparisons of strength measurements impossible to achieve. Thus, the purpose of this study was to assess the relationship between hamstring length and GM strength with and without normalization.

\footnotetext{
*Corresponding author. Jae-Seop Oh (E-mail: ysrehab@inje.ac.kr)
}

(C2018 The Society of Physical Therapy Science. Published by IPEC Inc. 


\section{SUBJECTS AND METHODS}

In total, 34 healthy male subjects were recruited from Inje University, Gyeongsangnam-do, Republic of Korea. The mean age of the subjects was $23.1 \pm 2.9$ years, and their mean height and weight were $174.4 \pm 5.2 \mathrm{~cm}$ and $74.1 \pm 18.8 \mathrm{~kg}$, respectively. Subjects were excluded if they had a history of lower extremity injury within 6 months prior to the study or an inability to correctly produce maximal GM strength in a pain-free manner. Prior to participation, all subjects read and signed an informed consent form approved by the Institutional Research Review Committee of Inje University (INJE 2016-07-004).

GM maximal isometric strength was measured using a custom-made fixed-base dynamometer consisting of a load cell (RSBA-50L; Radian, Seoul, Korea) connected using a resistance belt. The load cell was linked to a digital indicator that displayed the force value. To stabilize the dynamometer, one side was connected to a wooden board and the other side was connected to a resistance belt that measured strength.

First, GM strength was measured in the prone position with maximal hip joint extension and the knee joints flexed to $90^{\circ 9}$. The resistance belt was placed on the posterior thigh just above the knee. Each subject was instructed to perform maximal isometric hip extension for 5 seconds. Measurement was done three times, with 2-minute breaks between trials. Subject's hand was places behind waist to control the substitute motions of arm or hand. The peak force for each trial was recorded, and the average value was calculated. Next, GM strength was normalized for body weight and height. The following formula was used to calculate a dimensionless measure of torque ${ }^{10)}$ :

$\%($ body weight $\times \mathrm{h})=$ torque $(\mathrm{N} \times \mathrm{m}) \times 100 /$ body weight $(\mathrm{N}) \times \mathrm{h}(\mathrm{m})$.

Hamstring muscle length was assessed using the active knee extension method ${ }^{11)}$. The subjects were instructed to maintain $90^{\circ}$ hip flexion in the supine position. Next, the subjects were instructed to actively extend the knee joint. The degree of achieved active knee extension was measured using a goniometer. The average of three active knee extension measurements was used as the hamstring muscle length for the data analysis.

All data were analyzed using SPSS software (ver. 18.0; SPSS Inc., Chicago, IL, USA). Pearson's correlation coefficients were used to quantify the linear relationships between GM strength and hamstring length. The significance level was set at $\mathrm{p}<0.05$. The level of correlation was determined using the following values: $<0.3$ represented weak correlation, from 0.3 to 0.7 moderate correlation, and $>0.7$ strong correlation ${ }^{12)}$.

\section{RESULTS}

GM strength without normalization was negatively correlated with hamstring length $(\mathrm{r}=0.33, \mathrm{p}=0.51)$, whereas $\mathrm{GM}$ strength with normalization was positively correlated with hamstring length $(r=0.62, p<0.001)$.

\section{DISCUSSION}

The results of this study showed a significant, positive relationship between GM strength with normalization and hamstring length, whereas a non-significant negative correlation was found between GM strength without normalization and hamstring length.

Hamstring length was significantly correlated with GM strength when the latter was normalized by body weight and height. Bazett-Jones et al. ${ }^{13)}$ reported a positive relationship between body mass and hip muscle strength, demonstrating the need for normalization to reduce the influence of body size on measures of strength. Hortobágyi et al. ${ }^{14)}$ suggested that as the range of individuals' sizes increases, the strength of the relationship between strength and body size is likely to increase. The absence of strength normalization in studies aimed at distinguishing among individuals of similar body size may be acceptable, but the same approach applied to studies with individuals of quite different body sizes could lead to erroneous conclusions $^{8)}$. Considering the significant correlation between body size and strength, muscle strength cannot be predicted accurately without normalization for body size. Using normalized strength to determine actual strength could be more effective than using absolute strength.

Previously, van Wingerden et al. ${ }^{5)}$ reported that hamstring tightness could be a compensatory mechanism to provide sacroiliac stability in subjects with gluteal muscle weakness. The hamstring becomes tight because GM inhibition precludes the ability of the two muscles to work synergistically, resulting in chronic overload on the hamstring ${ }^{15}$. It is assumed that when the primary muscle responsible for hip extension (namely, the GM) is weakened, the synergistic muscle (i.e., the hamstring) compensates for this deficit, becoming overactive to serve as the primary muscle ${ }^{15)}$. Thus, it is thought that GM weakness is accompanied by hamstring tightness.

This study has several limitations. First, only healthy young males participated in this study. To strengthen the clinical implications of this study, additional studies are needed to assess GM weakness in subjects with low back pain or sacroiliac dysfunction. Second, electromyographic measurements were not made. Such data could help to support the suggestion of a correlation between GM strength and hamstring length.

The normalization of GM strength by body weight and height has the potential to lead to more appropriate conclusions and interpretations about the relationship between GM strength and hamstring length suggested here. These data may have 
implications for the preventative and therapeutic care of patients with GM weakness and hamstring tightness. The results of this study could be beneficial to clinicians that hamstring stretching exercises could be accompanied for the treatment of GM weakness.

\section{Funding}

This research was supported by Basic Science Research Program through the National Research Foundation of Korea (NRF) funded by the Ministry of Education (No. 2015R1D1A1A01056853). This work was supported by the 2015 Postdoctoral Research Program of Inje University.

\section{REFERENCES}

1) Hébert LJ, Maltais DB, Lepage C, et al.: Isometric muscle strength in youth assessed by hand-held dynamometry: a feasibility, reliability, and validity study. Pediatr Phys Ther, 2011, 23: 289-299. [Medline] [CrossRef]

2) Katoh M, Hiragi Y, Uchida M: Validity of isometric muscle strength measurements of the limbs using a hand-held dynamometer and belt: a comparison with an isokinetic dynamometer. J Phys Ther Sci, 2011, 23: 553-557. [CrossRef]

3) Nadler SF, DePrince ML, Hauesien N, et al.: Portable dynamometer anchoring station for measuring strength of the hip extensors and abductors. Arch Phys Med Rehabil, 2000, 81: 1072-1076. [Medline] [CrossRef]

4) Page P, Frank C, Lardner R: Assessment and treatment of muscle Imbalance: the Janda Approach. Chicago: Human Kinetics, 2010.

5) van Wingerden JP, Vleeming A, Buyruk HM, et al.: Stabilization of the sacroiliac joint in vivo: verification of muscular contribution to force closure of the pelvis. Eur Spine J, 2004, 13: 199-205. [Medline] [CrossRef]

6) Massoud Arab A, Reza Nourbakhsh M, Mohammadifar A: The relationship between hamstring length and gluteal muscle strength in individuals with sacroiliac joint dysfunction. J Manual Manip Ther, 2011, 19: 5-10. [Medline] [CrossRef]

7) Keating JL, Matyas TA: The influence of subject and test design on dynamometric measurements of extremity muscles. Phys Ther, 1996, 76: 866-889. [Medline] [CrossRef]

8) Jaric S: Muscle strength testing: use of normalisation for body size. Sports Med, 2002, 32: 615-631. [Medline] [CrossRef]

9) Yoshizawa T, Higashi K, Katou T: Measuring hip flexor and extensor strengths across various postures using a fixed belt. J Phys Ther Sci, 2017, 29: 572-575. [Medline] [CrossRef]

10) Fredericson M, Cookingham CL, Chaudhari AM, et al.: Hip abductor weakness in distance runners with iliotibial band syndrome. Clin J Sport Med, 2000, 10: 169-175. [Medline] [CrossRef]

11) Nourbakhsh MR, Arab AM: Relationship between mechanical factors and incidence of low back pain. J Orthop Sports Phys Ther, 2002, 32: 447-460. [Medline] [CrossRef]

12) Hoch MC, Staton GS, Medina McKeon JM, et al.: Dorsiflexion and dynamic postural control deficits are present in those with chronic ankle instability. J Sci Med Sport, 2012, 15: 574-579. [Medline] [CrossRef]

13) Bazett-Jones DM, Cobb SC, Joshi MN, et al.: Normalizing hip muscle strength: establishing body-size-independent measurements. Arch Phys Med Rehabil, 2011, 92: 76-82. [Medline] [CrossRef]

14) Hortobágyi T, Katch FI, Katch VL, et al.: Relationships of body size, segmental dimensions, and ponderal equivalents to muscular strength in high-strength and low-strength subjects. Int J Sports Med, 1990, 11: 349-356. [Medline] [CrossRef]

15) Geraci MC Jr: Overuse injuries of the hip and pelvis. J Back Musculoskeletal Rehabil, 1996, 6: 5-19. [Medline] [CrossRef] 